\title{
VALUATION AND COMPUTING ALGORITHM FOR BOT ASSOCIATED BUSINESS
}

\author{
Ho, S. Ping \\ National Taiwan University \\ spingho@ntu.edu.tw \\ Tang, Li-yu, \\ National Taiwan University \\ r91521702@ntu.edu.tw
}

It is not unusual that BOT firms are granted to develop or operate certain business/project beyond the main scope of a BOT project, such as the surrounding land development. By granting these BOT project associated business, government can improve the project expected return and financial viability, and encourage potential developers to participate in BOT projects. Nevertheless, for host government, it is very difficult and subjective to evaluate the motivating effects or policy effectiveness. For developers, inaccurate valuation of associated businesses may cause serious bias during BOT project bidding process. For fund providers, such as lenders, contract design depends on accurately evaluating the overall value and risk level of a BOT project. As a result, it is crucial to accurately price the associated business. In this paper, real options theory, a dynamic asset pricing approach, is used to evaluate the associated business. Theory of mechanism design based on game theory is incorporated with the real options to investigate the government policy effectiveness and optimal policy design. A computing algorithm for valuation and optimal debt contract is developed.

Keywords: BOT 、Mechanism Design 、 Real Option Theory

\section{INTRODUCTION}

It is not unusually that BOT firms are granted to develop or operate certain business/project beyond the main scope of a BOT project, such as the surrounding land development. This type of privilege typically exists when the project itself is not able to pay off the project cost and cannot create a sufficient amount of profit to compensate for the risks involved. These secondary businesses will be termed Associated Businesses in this paper. By granting associated business, government can improve the project expected return and financial viability, and encourage potential developers to participate in BOT projects. As a result, the associated business can be considered as the subsidy to the project, and therefore, the value of the associated business were it traded in the market is a cost to the government. In the paper, the cost is called the "policy cost." However, the value of the associated business is not necessarily the same as its market value due to the common practice of restricting the promoter's right of trading their equity shares the BOT project. The value distortion on an asset due to such restriction is discussed by Ingersoll (2002). As a result, the effectiveness of the granted associated business should be judged by how valuable the associated business is to the BOT project promoters. For host government, it is very difficult to evaluate the policy effectiveness.

The information asymmetry problem for fund providers is another difficult issue in BOT. The associated business is often distinctly different from the main scope of a BOT project in many perspectives, such as risk characteristics and management/developing flexibilities. For example, the developer often has options to decide the type or risk level of the associated business. Fund providers cannot observe or learn ex ante what risk level the promoter will choose for the associated business. In other words, the risk level information is private to the project promoter. As a result, it is important for fund providers to design different contracts that can have the promoter self-select into different type of contract according to their own private information, i.e., their intention for the risk level of the associated business.

Since the associate land development is one of the most often granted associated businesses in BOT, this study focuses on the land development rights. In this paper, modern financial theory and game theory are used to price the associated business, and furthermore to develop a model to examine the policy effectiveness and to design loan contracts. Theory of mechanism design based on game theory is incorporated with the real options to investigate the government policy effectiveness and optimal debt contract design.

We will introduce the methodologies used for model development in section 2. In section 3, we will, discuss the quantitative model for analyzing the 
subjective value and market value of the associated business. Lastly, we will give our suggests regarding the mechanism design of a BOT project.

\section{LITERATURE REVIEW}

To enhance a BOT project's financial viability, the associated business, a subsidy from such perspective, could be considered as a motivating policy toward a specific project set by the government (Chen, [3]). Chen [3] apply game theory to analyze the concessionaire's investing behavior. Current research in finance has been discussing the efficiency and valuation of the motivation effectiveness of the 'manager's compensation' (Lambert, Larcker, and Verrecchia, [11]; Carpenter, [2]; Ingersoll, [10]). This line of research focuses on the asset value distortion due to the restriction on the manger's own investment portfolio.

Option pricing theory was developed by Merton [14] and Black-Scholes [1] in 1973 and researchers made considerable progress recently in valuation and application of nontraditional options. The valuation model we used to evaluate the associated business of a BOT project is called 'barrier option pricing model,' discussed by Ingersoll [8, [9], and [10]. The fundamental assumptions beneath of this model make it more applicable to our research than other models. The main reason is that Ingersoll's model is built on the assumption of "utility maximization" as discussed by Merton [13], and deals with the problem under the situation of "liquidity restraint," which means the decision-maker is forced to maintain a certain proportion of his total assets on a certain kind of risky asset. Lambert, Larcker, and Verrecchia [11] also build their valuation model on the basis of "utility maximization" principle. In their model, they limit the randomness of decision-maker's portfolio. This assumption makes their model far from the real world. Moreover, since we consider the associated businesses a real option, an option to invest in the associated business. This assumption makes Ingersoll's model, which values a financial option, more applicable than other models such as Hall and Murphy [5] or Carpenter [2].

\section{THE VALUATION MODEL AND POLICY EFFECTIVENESS}

Ho and Liu [6] applied real options framework in evaluating the financial viability of a BOT project. Ho and Liu [7] also discussed the added value to an investment due to the option to wait for investing, also called timing option. According to option pricing theory, if a project has options to decide the investment timing under uncertainty, the investment criteria will more stringent than the traditional non-negative NPV criterion since the project needs to have higher NPV in order to exercise/kill the option to wait, which is to invest by the definition of exercising an option. In the BOT scheme, typically the promoter has the right to decide when and how to invest in an associated business, and hence, has the option to wait. To price the land development right with options to wait, in the model we combine McDonald and Siegel's [12] model and Ingersoll's $[8,9,10]$ model. McDonald and Siegel's [12] consider the investment with waiting option as a perpetual option, an option that will never expire. They find an investment threshold as shown in equation (1) so that when the benefit/cost ratio exceeds the threshold the investment is triggered. However, in many cases, the government will specify the length of time that the promoter can wait. To compute the timing option with limited option life, we incorporate Ingersoll's model for barrier option and use the threshold obtained from equation (1) as a proxy of the barrier in the pricing of a barrier option.

$$
V / F=C^{*}=\frac{\varepsilon}{\varepsilon-1}
$$

where

$$
\begin{aligned}
\varepsilon= & \sqrt{\left.\left(\frac{1}{2}-\frac{\delta_{f}-\delta_{v}}{\left(\beta_{x}^{2} \sigma_{m}^{2}+\xi_{x}^{2} v_{s}^{2}\right.}\right)\right)^{2}+2 \frac{\delta_{f}}{\left(\beta_{x}^{2} \sigma_{m}^{2}+\xi_{x}^{2} v_{s}^{2}\right)}} \\
& +\left(\frac{1}{2}-\frac{\delta_{f}-\delta_{v}}{\left(\beta_{x}^{2} \sigma_{m}^{2}+\xi_{x}^{2} v_{s}^{2}\right)}\right)
\end{aligned}
$$

and

$$
\begin{aligned}
& \begin{array}{l}
\beta_{x} \equiv \beta_{v}-\beta_{f} \quad \xi_{x}=\xi_{v}-\xi_{f} \\
\mu_{x}=r+\left(\mu_{v}-\mu_{f}\right)=r+\left(\beta_{v}-\beta_{f}\right)\left(\mu_{m}-r\right) \\
\quad=r+\beta_{x}\left(\mu_{m}-r\right)
\end{array} \\
& \text { with }
\end{aligned}
$$

$\mu_{v}=$ the expected benefit of the associated business

$\delta_{v}=$ the shortage effect of real asset in benefit of the associated business

$\beta_{v}=$ beta of benefit of associated business

$\mu_{m}=$ the expected return of total market

$\sigma_{m}=$ risk of total market return

$v_{s}=$ nonsystematic risk of the BOT project

$\xi_{v}=$ the correlation of benefit of associated business and benefit of main business

$\xi_{f}=$ the correlation of cost of associated business and benefit of main business, assume $\xi_{f}^{2} \rightarrow 0$

$\mu_{f}=$ the expected cost of the associated business

$\delta_{f}=$ the shortage effect of real asset in cost of the associated business

$\beta_{f}=$ beta of cost of associated business

$r=$ risk-free interest rate

$Q_{t}=$ value of associated business when the option is perpetual

$C^{*}=$ optimal investment-timing

Research on the effectiveness of manager's 
compensation through stock options and their related assets shows that stock options are less valuable, compared to market value, to the manager when the options are offered as compensation and the trading of these options is restricted. The option value to the manager in this case is called "subjective value" in this paper. Usually, the subjective value will be smaller than the market value because the manger is forced to hold much larger portion, compared to the optimal portfolio without trading restriction, of the stock option offered as compensation. Such portfolio distortion caused by the liquidity restraint will limit the effectiveness of the motivation from compensation. Similarly, in a BOT project, considering the restriction on the promoter's project equity trading, when the promoter senses the trading restriction, the project will have a subjective value. According to Ingersoll [10], when computing the subjective value under options pricing framework, the risk free interest rate used for standard option pricing should be adjusted as shown in equation (2) to reflect the impact of trading restriction. However, there is another variable affecting the subjective value. This variable is the optimal investment timing calculated by equation (1) as we discussed previously. There are two situations in computing the optimal investment timing. The first one is when promoters make their own timing decision and the second one is when promoters make decisions based outside consultant's assessment. Since the outside consult does not have the share trading restriction, the outside consultant will suggests developing decisions based on the result standard option pricing framework, assuming that the consultant is professionally good and be able to assess the timing option and optimal investment timing. The timing obtained by the consultant is considered as "objective optimal timing." The second situation is when promoters make their own timing decision. Under project equity trading restriction, the computing of optimal timing in equation (1) is again affected by the adjustment of risk free interest rate by equation (2). Such investment timing is called "subjective optimal timing" in this paper. In other words, the subjective value of a land development depends on both the adjustment of risk free rate and the person who assesses the optimal timing. As a result, the value of the land development right to a promoter could either be the subjective value with objective optimal timing, denoted as $Q_{t}^{\prime \prime}$, or be the subjective value with subjective optimal timing, denoted as $\hat{Q}_{t}^{\prime}$. As opposed to subjective value, the objective value of a land development right, denoted as $Q_{t}^{\prime}$, should be assessed from the market perspective, and therefore, be evaluated under standard option pricing framework with objective optimal timing. The meanings and characteristics of various types of values of a land development right are organized in Table 1.

$$
\hat{r} \equiv r-(1-\gamma) \alpha^{2} v_{s}^{2}
$$

where $r$ =objective risk-free rate

$\gamma=$ risk-aversion degree of promoter

$\alpha=$ liquidity restraint

$v_{s}=$ nonsystematic risk of the BOT project

$\hat{r}=$ subjective risk-free rate

By this adjusting, the subjective optimal timing could be defined as

$V / F=C^{*}=\frac{\hat{\varepsilon}}{\hat{\varepsilon}-1}$

where

$$
\begin{aligned}
& \hat{\varepsilon}=\sqrt{\left(\frac{1}{2}-\frac{\hat{\delta}_{f}-\hat{\delta}_{v}}{\left(\beta_{x}^{2} \sigma_{m}^{2}+\xi_{x}^{2} v_{s}^{2}\right)}\right)^{2}+2 \frac{\hat{\delta}_{f}}{\left(\beta_{x}^{2} \sigma_{m}^{2}+\xi_{x}^{2} v_{s}^{2}\right)}} \\
& \quad+\left(\frac{1}{2}-\frac{\hat{\delta}_{f}-\hat{\delta}_{v}}{\left(\beta_{x}^{2} \sigma_{m}^{2}+\xi_{x}^{2} v_{s}^{2}\right)}\right) \\
& \text { and } \\
& \beta_{x} \equiv \beta_{v}-\beta_{f} \quad \xi_{x}=\xi_{v}-\xi_{f} \quad \mu_{x}=\hat{r}+\beta_{x}\left(\mu_{m}-\hat{r}\right) \\
& \hat{\delta}_{v}=\delta_{v}+(1-\gamma) \alpha v_{s}^{2}\left(\xi_{v}-\alpha\right) \\
& \hat{\delta}_{f}=\delta_{f}+(1-\gamma) \alpha v_{s}^{2}\left(\xi_{f}-\alpha\right)
\end{aligned}
$$

From this formula we have built up several valuation models, as following:

Table 1 The valuation models

\begin{tabular}{|c|l|l|}
\hline $\begin{array}{c}\text { Value of a } \\
\text { land } \\
\text { development }\end{array}$ & \multicolumn{1}{|c|}{ Meaning } & $\begin{array}{c}\text { Option } \\
\text { discounting } \\
\text { system and the } \\
\text { invest-timing }\end{array}$ \\
\hline$Q_{t}^{\prime}$ & $\begin{array}{l}\text { The objective } \\
\text { value/policy cost for a } \\
\text { land development right }\end{array}$ & $\begin{array}{l}\text { Market risk } \\
\text { free rate and } \\
\text { Objective } \\
\text { optimal timing }\end{array}$ \\
\hline$Q_{t}^{\prime \prime}$ & $\begin{array}{l}\text { The subjective value for a } \\
\text { land development right } \\
\text { when the promoter makes } \\
\text { investment timing } \\
\text { decision based on outside } \\
\text { consultant's suggestion }\end{array}$ & $\begin{array}{l}\text { Adjusted risk } \\
\text { free rate and } \\
\text { Objective } \\
\text { optimal timing }\end{array}$ \\
\hline$\hat{Q}_{t}^{\prime}$ & $\begin{array}{l}\text { The subjective value for a } \\
\text { land development right } \\
\text { when the promoter makes } \\
\text { investment timing } \\
\text { decision by themselves }\end{array}$ & $\begin{array}{l}\text { Adjusted risk } \\
\text { free rate and } \\
\text { Subjective } \\
\text { optimal timing }\end{array}$ \\
\hline
\end{tabular}

The structure of models are showed as follow:

Model-(1) $Q_{t}^{\prime}=F_{t} \cdot C_{\text {barr }}$ 
with $F_{t}=$ the expected optimal scale of land development, and

$$
\begin{aligned}
C_{\text {barr }}= & \mathbb{C}\left(X, t ; T ;\left\{X_{T}>1\right\} \&\left\{X_{\max }<C^{*}\right\}\right) \\
& -\mathbb{D}\left(X, t ; T ;\left\{X_{T}>1\right\} \&\left\{X_{\max }<C^{*}\right\}\right) \\
& +\left(C^{*}-1\right) \Gamma\left(X, t ; T ; C^{*}\right)
\end{aligned}
$$

and

$$
\begin{aligned}
& \mathbb{C}\left(X, t ; T ;\left\{X_{T}>1\right\} \&\left\{X_{\max }<C^{*}\right\}\right) \\
& =X e^{-\delta_{x}(T-t)}\left\{\begin{array}{l}
\Phi(H(1))-\Phi\left(H\left(C^{*}\right)\right) \\
-\left(C^{*} / X\right)^{2(\lambda+1)}\left[\Phi\left(H\left(X^{2} / C^{* 2}\right)\right)-\Phi\left(H\left(X^{2} / C^{*}\right)\right)\right]
\end{array}\right\} \\
& \mathbb{D}\left(X, t ; T ;\left\{X_{T}>1\right\} \&\left\{X_{\max }<C^{*}\right\}\right) \\
& =e^{-r(T-t)}\left(\begin{array}{l}
\Phi(h(1))-\Phi\left(h\left(C^{*}\right)\right) \\
-\left(C^{*} / X\right)^{2 \lambda}\left[\Phi\left(h\left(X^{2} / C^{* 2}\right)\right)-\Phi\left(h\left(X^{2} / C^{*}\right)\right)\right]
\end{array}\right) \\
& \mathbb{T}\left(X, t ; T ; C^{*}\right)=\left(C^{*} / X\right)^{\lambda-\kappa} \Phi\left(H_{\kappa}\left(C^{*}\right)\right) \\
& +\left(C^{*} / X\right)^{\lambda+\kappa} \Phi\left(h_{\kappa}\left(C^{*}\right)\right)
\end{aligned}
$$

where $\Phi(\cdot)=$ c.d.f. of standard normal distribution and

$$
\begin{aligned}
& H_{\kappa}(z) \equiv \frac{\ln (X / z)+\kappa \sigma_{X}^{2}(T-t)}{\sigma_{X} \sqrt{T-t}} \\
& h_{\kappa}(z) \equiv H_{\kappa}(z)-2 \kappa \sigma_{X} \sqrt{T-t} \\
& \lambda \equiv \frac{r-\delta_{X}}{\sigma_{X}^{2}}-\frac{1}{2} \quad \kappa \equiv \sqrt{\lambda^{2}+2 r / \sigma_{X}^{2}} \\
& H(z) \equiv \frac{\ln (X / z)+\left\{r-\delta_{X}+\frac{1}{2} \sigma_{X}^{2}\right\}(T-t)}{\sigma_{X} \sqrt{T-t}} \\
& h(z) \equiv H(z)-\sigma_{X} \sqrt{T-t} \\
& \sigma_{X}^{2}=\beta_{x}^{2} \sigma_{m}^{2}+\xi_{x}^{2} v_{s}^{2} \\
& \beta_{x}=\beta_{v}-\beta_{f} \\
& \delta_{x}=r+\left(\delta_{v}-\delta_{f}\right)-\sigma_{m}^{2} \beta_{f}\left(\beta_{v}-\beta_{f}\right)+\xi_{v} \xi_{f} v_{s}^{2} \\
& \quad=r+\left(\delta_{v}-\delta_{f}\right)-\sigma_{m}^{2} \beta_{f} \beta_{x}+\xi_{v} \xi_{f} v_{s}^{2} \\
& \xi_{x}=\xi_{v}-\xi_{f} \\
& X_{t}=V_{t} / F_{t}
\end{aligned}
$$

Model-(2) $\quad Q_{t}^{\prime \prime}=F_{t} \cdot C_{\text {barr }}^{\prime}$

The definition of factors in this model is just the same with model-(1), but the risk free rate is adjusted as shown in equation (2) to reflect the impact of trading restriction when discounting the asset value.

Model-(3) $\hat{Q}_{t}^{\prime}=F_{t} \cdot \hat{C}_{\text {barr }}$

The definition of factors in this model is just the same with model-(2), but the optimal timing is adjusted as equation (3) to reflect the impact of trading restriction when promoters deciding the timing of investment.

Therefore, we evaluate the effectiveness of granting a land development by the ratio of subjective value to objective value. As shown in Table 1, we call the ratio $Q_{t}^{\prime \prime} / Q^{\prime}$ the "policy effectiveness for firms with land development expertise" and the ratio $\hat{Q}^{\prime} / Q^{\prime}$ the "policy effectiveness for firms without land development expertise." Next we will perform sensitivity analysis on several important factors/variables as shown in Table 2 to examine the policy effectiveness under different situations.

\section{Table 2 Factors of sensitivity analysis}

\begin{tabular}{|c|c|c|}
\hline Factors & Meaning of factors & Type of factors \\
\hline$T-t$ & Duration & $\begin{array}{c}\text { Project } \\
\text { characteristics }\end{array}$ \\
\hline$\beta_{V}$ & $\begin{array}{c}\text { Beta of benefit of } \\
\text { associated business }\end{array}$ & $\begin{array}{c}\text { Project } \\
\text { characteristics }\end{array}$ \\
\hline$\beta_{f}$ & $\begin{array}{c}\text { Beta of cost of } \\
\text { associated business }\end{array}$ & $\begin{array}{c}\text { Project } \\
\text { characteristics }\end{array}$ \\
\hline$v_{S}$ & $\begin{array}{c}\text { Nonsystematic risk of } \\
\text { the BOT project }\end{array}$ & $\begin{array}{c}\text { Project } \\
\text { characteristics }\end{array}$ \\
\hline$v_{V}$ & $\begin{array}{c}\text { Nonsystematic risk of } \\
\text { benefit of associated } \\
\text { business }\end{array}$ & $\begin{array}{c}\text { Project } \\
\text { characteristics }\end{array}$ \\
\hline$\gamma$ & $\begin{array}{c}\text { risk-aversion degree of } \\
\text { firm }\end{array}$ & $\begin{array}{c}\text { Firm } \\
\text { characteristics }\end{array}$ \\
\hline$\alpha$ & $\begin{array}{c}\text { liquidity restraint } \\
\text { characteristics }\end{array}$ \\
\hline
\end{tabular}

The results show as follow:

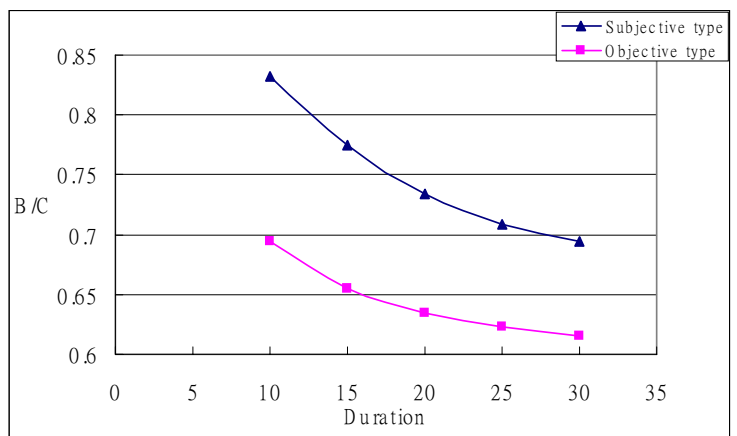

Fig. 1 S.A. of policy efficiency - $T-t$ 


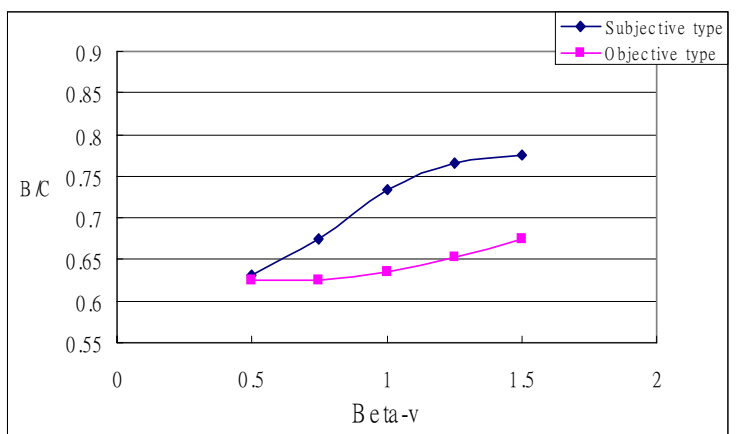

Fig. 2 S.A. of policy efficiency - $\beta_{V}$

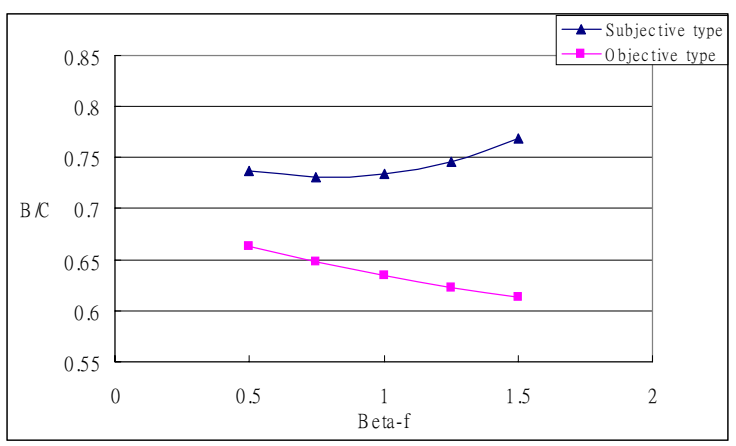

Fig. 3 S.A. of policy efficiency - $\beta_{f}$

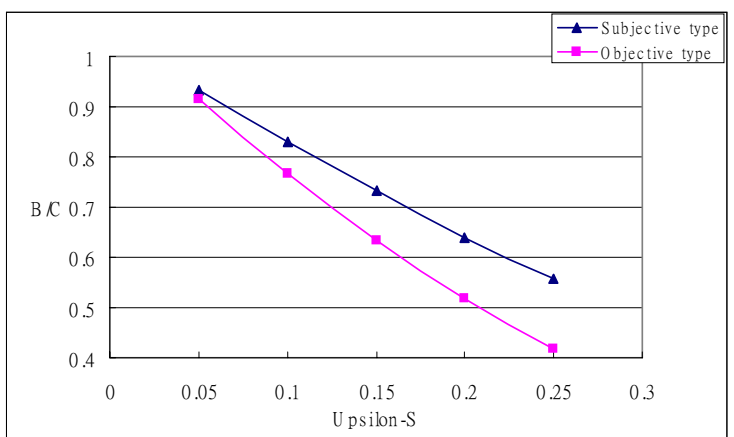

Fig. 4 S.A. of policy efficiency - $v_{S}$

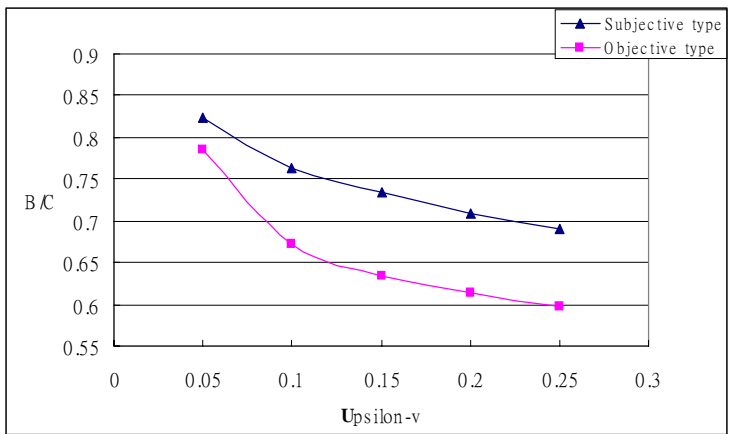

Fig. 5 S.A. of policy efficiency - $v_{V}$

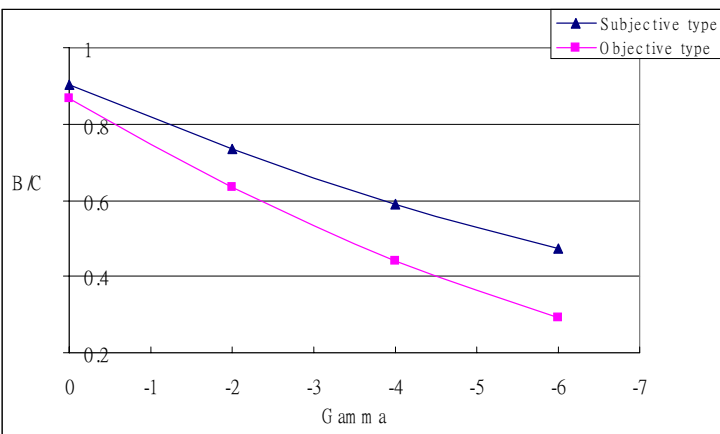

Fig. 6 S.A. of policy efficiency - $\gamma$

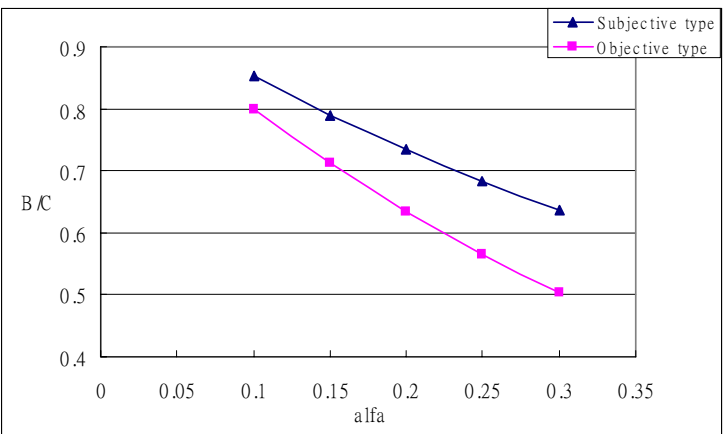

Fig. 7 S.A. of policy efficiency - $\alpha$

The most important thing the government should concern when promoting a BOT project is "policy efficiency.' However, people cannot probe into the motivating effects or policy efficiency without valuing the concessionaire's subjective values of these associated businesses in quantitative sense. So, in our research we build up valuation models of associated business. From the sensitivity analysis, we can get the result showing as follows:

Table 3 Analysis of policy efficiency

\begin{tabular}{|c|c|c|c|}
\hline $\begin{array}{c}\text { Change of } \\
\text { factors }\end{array}$ & $\begin{array}{c}\text { Meaning of } \\
\text { factors }\end{array}$ & $\begin{array}{c}\text { Change of } \\
\text { policy } \\
\text { effectiveness }\end{array}$ & $\begin{array}{c}\text { Note: which } \\
\text { type more } \\
\text { significant }\end{array}$ \\
\hline$T-t \uparrow$ & Duration & $\downarrow$ & Subjective type \\
\hline$v_{S} \uparrow$ & $\begin{array}{c}\text { Nonsystematic } \\
\text { risk of the } \\
\text { BOT project }\end{array}$ & $\downarrow$ & Objective type \\
\hline$\beta_{V} \uparrow$ & $\begin{array}{c}\text { Beta of benefit } \\
\text { of associated } \\
\text { business }\end{array}$ & $\uparrow$ & Subjective type \\
\hline$v_{V} \uparrow$ & $\begin{array}{c}\text { Nonsystematic } \\
\text { risk of benefit } \\
\text { of associated } \\
\text { business }\end{array}$ & $\downarrow$ & Objective type \\
\hline$\beta_{f} \uparrow$ & $\begin{array}{c}\text { Beta of cost of } \\
\text { associated } \\
\text { business }\end{array}$ & --- & Not significant \\
\hline
\end{tabular}




\begin{tabular}{|c|c|c|c|}
\hline $\begin{array}{c}\text { Change of } \\
\text { factors }\end{array}$ & $\begin{array}{c}\text { Meaning of } \\
\text { factors }\end{array}$ & $\begin{array}{c}\text { Change of } \\
\text { policy } \\
\text { effectiveness }\end{array}$ & $\begin{array}{c}\text { Note: which } \\
\text { type more } \\
\text { significant }\end{array}$ \\
\hline$\gamma \uparrow$ & $\begin{array}{c}\text { risk-aversion } \\
\text { degree of firm }\end{array}$ & $\downarrow$ & Objective type \\
\hline$\alpha \uparrow$ & $\begin{array}{c}\text { liquidity } \\
\text { restraint }\end{array}$ & $\downarrow$ & Objective type \\
\hline
\end{tabular}

From Table 3, we can find that policy efficiency will decrease if nonsystematic risk increasing. If other things remained, it means high volatility of net income before tax and interest of project will make policy inefficient. So the government should separate the firms with high volatility return from others. But usually the volatilities of projects are firms' private information.

\section{Conclusions}

From our research we find that several mechanisms will interact, such as that liquidity restraint will decrease the subjective value of associated business. The government should pay attention to this kind of interaction, or the motivating policy and ensuring policy will make each other inefficient.

Moreover, the government should not involve too much in the negotiation between potential promoters and banks, and the government should not limit the space of the outcome of interest rate in BOT projects. The financing contract could tell a lot of things about the type of a potential promoter, and the government should give more freedom to banks in negotiating with BOT firms to prevent the happening of adverse selection.

\section{REFERENCES}

[1] Black, F., and M. Scholes ( 1973 ), "The Pricing of Options and Corporate Liabilities." Journal of Political Economy 81, 637-659.

[2] Carpenter, J. ( 1998 ), "The Exercise and Valuation of Executive Stock Options" Journal of Financial Economics 48, 127-158.

[3] Chen, Y-L ( 2002 ), The Effect of Associate Business on the concessionaire's investment behavior in the main concession business, NCTU master dissertation.

[4] Dowd, K. ( 1992 ) , "Optimal financing contracts.” Oxford Economic Papers 44, 672-693.

[5] Hall, B. and K. Murphy ( 2000 ), "Stock Options for Undiversified Executives." NBER Working Paper.

[6] Ho, S. Ping and Liu, Liang Y., (2002) "An Option Pricing Based Model for Evaluating the Financial Viability of Privatized Infrastructure Projects." Construction Management and Economics, Vol 20, $143-156$.

[7] Ho, S. Ping and Liu, Liang Y., (2003) "How to Evaluate and Invest in Emerging $\mathrm{A} / \mathrm{E} / \mathrm{C}$
Technologies." Journal of Construction Engineering and Management, ASCE, 129(1), 16-24.

[8] Ingersoll, J. ( 1998 ) , “Approximating American options and other financial contracts using barrier derivatives." Journal of Computational Finance 2, $85-112$.

[9] Ingersoll, J. ( 2000 ), "Digital Contracts : Simple Tools for Pricing Complex Derivatives." The Journal of Business 73, 67-88.

[10] Ingersoll, J. ( 2002 ) , "The Subjective and Objective Evaluation of Incentive Stock Options." Yale ICF working paper No. 02-07.

[11] Lambert R., D. Larcker, and R. Verrecchia ( 1991 ) , "Portfolio Considerations in Valuing Executive Compensation." Journal of Accounting Research 29, 129-149.

[12] McDonald, R., and D. Siegel (1986), "The Value of Waiting to Invest." Quarterly Journal of Economics 101, 707-27.

[13] Merton, R.(1969), "Lifetime Portfolio Selection under Uncertainty: The Continuous-Time Case." The Review of Economics and Statistics 51, 247-257.

[14] Merton, R. ( 1973 ), "Theory of Rational Option Pricing." The Bell Journal of Economics and Management Science 4, 141-183. 